\title{
Problems in meiofauna energy-flow studies
}

\author{
Peter M. J. Herman, Guido Vranken \& Carlo Heip \\ Marine Biology Section, Instituut voor Dierkunde, Rijksuniversiteit Gent, K. L. Ledeganckstraat 35, B-9000 \\ Gent, Belgium
}

Keywords: meiofauna, marine meiobenthos, energy-flow, production, respiration, biomass

\begin{abstract}
The direct estimation of energy flow through marine meiobenthic populations poses several difficulties, mainly relating to sampling problems. The usefulness of some indirect estimation methods is discussed.

Direct production estimates and respiration measurements for three brackish water crustacean populations are given, indicating a relative constant proportion between population production and respiration. The production: assimilation ratio for these populations fluctuates between 0.3 and 0.4 . This is contrasted to literature data revealing much higher production: assimilation ratios as determined in the laboratory for nematode populations. Using data on laboratory cultures of the nematode Monhystera disjuncta some factors that can possibly generate this discrepancy are discussed. An analysis of P:B in different life stages of this population justifies the use of a life-cycle turnover of about 3 for meiobenthic populations, provided some conditions are met. Among these is that no drastic change in productivity occurs between juveniles and adults, and that the biomass of hatchlings, not of freshly laid eggs, is considered as generative production.
\end{abstract}

\section{Introduction}

Since the start of the International Biological Programme, considerable scientific effort has been devoted to the study of the productivity of marine populations. These studies focus in the first place on a good description of average standing stocks and transfer rates between compartments in black box models. The final aim of the study of ecosystems from the energetic point of view is an understanding and quantification of the time-dependent dynamics of the system.

In this framework, relatively little attention has been paid to the meiofauna. Although a great number of data have been gathered on density, diversity and species composition of meiofauna, it is still very problematic to derive from these an estimation of the rate of energy flow through these populations. As a consequence, the detailed study of the interactions in which meiobenthic popula- tions are involved is impaired. The quantification and indeed the proof of the existence of competition in meiofauna remains a far and elusive goal. The same is true for several predator-prey type relationships: grazing by meiofauna on microflora, predation by epibenthos on the meiofauna, and predation within the meiofauna. Energy flow measurements are required to evaluate both the grazing pressure on lower trophic levels, and the amount of energy and material made available to higher trophic levels.

Methods for the estimation of production in aquatic populations are extensively reviewed by Waters (1977). They can be reduced to two types: summation of eliminated biomass, or summation of growth increments (including reproductive output). According to the method used, one needs good data either about growth, reproduction and recruitment, or about mortality and changes in biomass. In populations with overlapping genera- 
tions and continuous reproduction, this procedure requires fitting of a demographic model to the available data, or alternatively the extrapolation of culture data to field situations. Especially in marine populations, both frequent sampling with sampling intervals in the order of days, and culturing in the laboratory are often impossible.

In the instances where direct estimates are impossible, production may be estimated indirectly by assuming a proportionality between respiration and production energy flows in the population. In a study comprising ecologically very different populations, Hymphreys (1979) could define several groups, all of which showed a significant log-log relationship between production and respiration with a slope not significantly different from 1 . This implies that within these groups the production efficiency, approximated by $P /(P+R)$, is independent of the population's size (where $P$ is production and $R$ respiration, both expressed in the same units, e.g. Joules). Banse (1979) also showed that the production efficiency ('Net growth efficiency') in a number of invertebrates from temperate regions is independent of the animals' size at first maturity. The assumption of proportionality between respiration and production may therefore be a reasonable base for indirect production estimation.

The empirical relationship between yearly $P: B$ (where B is mean biomass) and adult size, established by Banse \& Mosher (1980) is another possibility to estimate production indirectly. Although it is difficult to establish the assumptions by which this relationship can be expected, the empirical data suggest that it may be useful. Furthermore, it is of particular interest to meiobenthologists because these authors propose another, lower line for meiobenthos than for similarly sized species from other ecological groups.

In this paper we shall discuss some field and laboratory data on production and respiration of meiobenthic populations. Our discussion will focus on the applicability of the above-mentioned shortcut methods for production estimation.

\section{Production and respiration}

In our work on a shallow brackish water pond, the Dievengat in north-western Belgium, we mea- sured both the production and the respiration of some meiobenthic crustaceans. Respiration as a function of body weight at $20^{\circ} \mathrm{C}$ was determined by Cartesian Diver microrespirometry for most developmental stages of one ostracod (Herman \& Heip, 1982) and five copepod species (Herman \& Heip, 1983). The metabolic intensity, measured by the intercept $a$ in the allometric relation $\log R=$ $a+\mathrm{b} \log W$ (where $R$ is respiration, $W$ body weight and $a$ and $b$ constants) is similar in four of these species. In the two larger and longer-lived species, the copepod Canuella perplexa and the ostracod Cyprideis torosa, it is much lower.

The production in the field was estimated directly for three of these populations. The results of these studies are summarized in Table 1.

The ostracod Cyprideis torosa has only one generation annually in this habitat, but there is considerablc overlap between successive generations, due to overwintering of the older larvae. Its production was estimated in two ways (Herman et al., 1983). In the first method the distribution over the developmental stages of the empty shells in the bottom was used to estimate stage-specific mortality rates, and the duration of the stages. The second method is a modification of the size-frequency ('IIynes') method. Both results are in good agreement.

The population of the harpacticoid copepod $T a$ chidius discipes was sampled every three days in the spring of 1979. The production of the copepodites and adults was estimated by two estimation procedures (Herman et al., 1984). These are based on Rigler \& Coolcy's (1974) method, and on the sizefrequency method. The production efficiency of $36 \%$ is calculated with neglection of the nauplii, for which neither good production nor respiration measurements are available. Inclusion of (rather rough) estimates of naupliar production and respiration raises the efficiency slightly, to $42 \%$. For this naupliar production estimate, an exponential model for mortality and body growth was assumed. Thus estimated, the naupliar production accounts for $41 \%$ of the total production.

The harpacticoid copepod Paronychocamptus nanus was sampled every five days in 1980 . The production estimation of copepodites and adults (Herman \& Heip, in prep.) was based on the sizefrequency method. Again the production efficiency (37\%) had to be estimated with neglection of the nauplii. However, with the same method as for $T$. 
discipes, a crude estimate of the naupliar contribution to overall production was made: $25 \%$. Our estimates can be compared to the $35 \%$ contribution found by Fleeger \& Palmer (1982) for Microarthridion littorale, and the $39 \%$ estimated for $\boldsymbol{H}$. jadensis (Feller, 1982). They confirm the important role of the nauplii in the population production, stressed by Hicks \& Coull (1983). However, as our calculations for $T$. discipes indicate, they probably have no profound influence on the estimation of the population's production efficiency.

As shown in Table 1, the production efficiencies of these three populations are nearly equal to one another. This neat proportionality between respiration and production is remarkable because the populations differ considerably in a number of characteristics (Table 2). The values for the production efficiency are in good agreement with the values expected from Humphreys' (1979) regression between $\log \mathrm{P}$ and $\log \mathrm{R}$ for non-insect detritivores. Also in good agreement is the value $(38 \%)$ found by Marchant \& Nicholas (1974) for the nematode Pelodera. These production efficiencies, however, are much lower than those obtained for nematodes in culture by Warwick (1981b), Schiemer et al. (1980), Schiemer (1982a, b) and Tietjen (1980). These authors all find very high production efficiencies, in the order of $70 \%$ to $90 \%$. It is an important question if, and how the major discrepancy between these two groups of values could be explained. We think that several factors should be considered.

\section{Field versus laboratory conditions}

The nematode data are obtained from lab cultures. The conditions in these cultures are obviously different from the conditions in the field. In his study on Caenorhabditis briggsae, Schiemer(1982a,
Table 1. Summary of energy-flow studies in three meiobenthic crustacean populations from a brackish-water habitat (The 'Dievengat' in northern Bclgium).

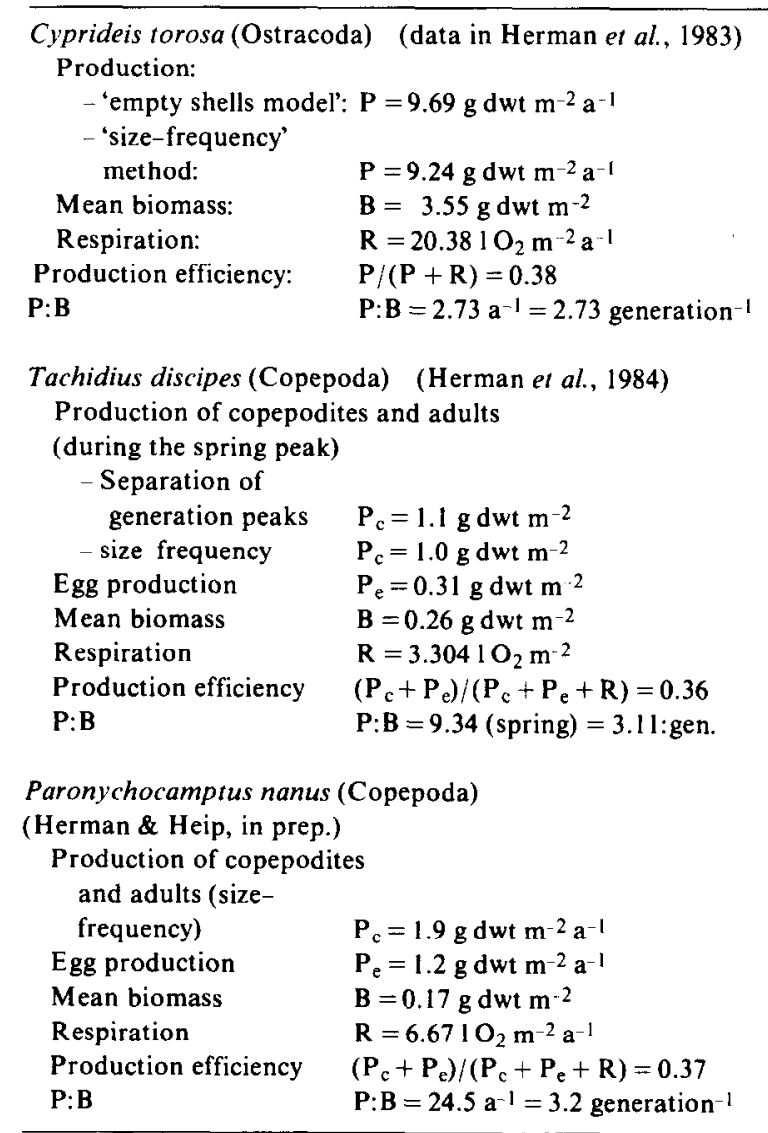

b) showed, for instance, that feeding conditions have a profound influence on the production efficiency. Other environmental factors will undoubtedly have a similar effect. The measured differences in efficiency could therefore imply that meiofauna in nature lives in fairly unfavorable conditions. However, this difference between lab and field con-

Table 2. Characteristics of the three meiobenthic populations for which energy budgets were constructed.

\begin{tabular}{llll} 
& C. torosa & T. discipes & P. nanus \\
\hline Adult size ( $\mu$ g dwt ind. 1) & $19.8 \mathrm{a}$ & $0.6(\delta)-1.0(9)$ \\
Metabolic intensityb & 0.25 & 1.8 & 1.0 \\
Number of generations: year & 1 & 1.1 & 8 \\
Food source & detritus & $3^{\mathrm{c}}$ & algae \\
\hline
\end{tabular}

\footnotetext{
a without the weight of the shells, see Herman \& Heip (1982)

b expressed as the parameter $a$ in $\log \mathrm{R}=a+b \log \mathrm{W}$, with $\mathrm{R}$ in $\ln \mathrm{O}_{2}$ ind. $^{-1}$ at $20^{\circ} \mathrm{C}$, and $\mathrm{W}$ in $\mu \mathrm{g}$ dwt ind.-1

: only present during a $2-3$ months spring period.
} 
ditions alone is insufficient as an explanation. Both Tachidius discipes and Paronychocamptus nanus have been cultured in the laboratory ( $\mathrm{Smol} \&$ Heip, 1974; Heip \& Smol, 1976; Heip, 1977). Applying our respiration data to the stable age distribution derived from the culture data yields an efficiency of about $40 \%$ for both species at $15^{\circ} \mathrm{C}$. Furthermore, the efficiency of Pelodera (Marchant \& Nicholas, 1974) has also been estimated in the laboratory.

\section{Differences in metabolic pathways}

Respiration in function of the body weight has been measured for the two congeneric nematodes Caenorhabditis briggsae (Schiemer, 1982a) and $C$. elegans (De Cuyper \& Vanfleteren, 1982). In both studies the respiration rate of the juvenile stage $I$ is relatively low: the observations lie under the allometric relation determined for the other stages. De Cuyper \& Vanfleteren (1982) could explain this phenomenon by the prevalence of a different metabolic pathway, the glyoxylate cycle, by which the fat stores are consumed in eggs and early juveniles of nematodes. In this pathway less oxygen is consumed for the same amount of energy metabolized. Obviously this is of importance in the estimation of assimilation as $A=P+R$, since no simple conversion factor of $\mathrm{R}$ to metabolized energy is available.

In the case of Caenorhabditis, this factor may only have a minor importance for the population's energy budget. For partially anaerobic species, however, it may be much more important.

\section{Neonate weight versus egg weight}

A third factor, which may well be the most important one, creates considerable difficulties for the concept of production. In nematodes, the weight of a neonate is consistently lower than the weight of a freshly deposited egg. The weight loss during egg development is sometimes $3 / 4$ of the fresh egg weight. Presumably the adults put organic matter into the eggs in a relatively unorganized state, and the weight loss in the eggs is the energetic cost of both maintenance and of the organization of this material into living tissue.

Due to this energy loss in the egg stage it is unclear what should be considered as 'production': the weight of the eggs produced or the weight of the neonates. If the organic matter of the egg mass is called production, the population's energy budget should comprise a term for the 'negative production' in the egg development. In this stage an amount of organic matter disappears from the population: the energy lost during the development is dissipated as heat. The inclusion of the eggs' 'negative production' may considerably lower the total population's production efficiency, and bring it back to more realistic values. For the reproducing females, however, it remains very high (Warwick (1981) and Tietjen (1980) record values over $90 \%$ ). This high efficiency is artificial if the energy cost of storing organic material in the eggs is lower than the energy cost of storing an equivalent quantity of material in the individual's own body growth.

An alternative definition of generative production could resolve some of the conceptual difficulties discussed. When the biomass of the neonates is defined as production, the total population's production efficiency is the same as the value obtained by incorporating the eggs' 'negative production'. The reproducing females' efficiency is lowered, and the two allocations of organic matter - own tissue growth and neonates' tissue - are more comparable as far as energetic cost is considered. In this definition of production the females become "conceptually viviparous'. However, this definition suffers from inconsistency with classical production theory: once the eggs are formed, they do represent an amount of energy which is available to higher trophic levels.

Although there remain conceptual problems, whatever definition of generative production is chosen, the fact that a lot of energy stored is lost from the population during egg development should be taken into account for the calculation of energy budgets. In most nematode populations for which very high efficiencies have been described, the bulk of the production is egg production. When the developmental energy loss is subtracted from these production figures, the efficiency will be considerably lower. For example, adjusting Schiemer's $(1982 \mathrm{a}, \mathrm{b})$ data for Caenorhabditis briggsae (at a food density of $10^{10}$ bacterial cells $\mathrm{ml}^{-1}$ ), yields a cumulative efficiency over a nematode's life span of about $40 \%$ instead of $62 \%$, although a peak value of nver $60 \%$ is still observed in early reproductive females.

In conclusion we think that the high production efficiencies in laboratory cultures are overestimations, and that with the present data there is noclear 
evidence that meiobenthic efficiency is higher than the efficiency in other groups. On the other hand, we need more data to be able to estimate the range of production efficiencies in meiobenthic populations. The estimation of production from respiration by assuming an efficiency of e.g. $40 \%$ is still very tentative.

\section{Production : Biomass (P:B) and body weight}

Some of the points made above are also of importance for a discussion of the scaling of P:B by body weight in meiofauna. The few field production estimates of meiobenthic populations show a P:B per generation time of about 3 . This figure was used by Heip et al. (1982) to estimate P:B of nematodes from culture data on generation times. It was first generalized for the meiobenthos by Gerlach (1971), who derived it from a partially hypothetical nematode life history. Both papers cite, as a justification for the generalization, the model study of Waters (1969). In this paper it was shown that for a wide variety of growth and mortality models, the lifetime P:B does not vary greatly around a modal value of about 3.5 .

However, on closer inspection it appears that nematodes are very different from the type of populations Waters (1969) modelled. He derived the lifetime, not the generation time turnover and showed that for stationary cohort populations this equals the P: B per period between two reproductive peaks. Nematodes on the contrary have continuous reproduction and their reproductive output is an important contribution to overall production: it cannot be neglected as Waters (1969) does. The main questions to ask, if one wishes to generalize about nematode P:B, are therefore: can the term 'generation time be exactly defined, and is there a justification to use the figure P:B -3 “per generation time"?' (In contrast to the demographic literature, where several exactly defined measures of generation time are used, the term has a loose meaning in production studies.)

To clarify these points, we shall use data on Monhystera disjuncta, cultured in agar dishes at $12{ }^{\circ} \mathrm{C}$ and $30 \%$ salinity (Vranken et al., in prep.). Bacterial food in these cultures was abundant, but its composition was not controlled. For this nematode, complete life tables and fecundity tables were determined. From these tables many demographic parameters were computed: the intrinsic rate of natural increase $r_{m}$, the stable age distribution at exponential growth, the birth rate $b$, the minimum gencration timc $T_{\min }$, the cohort generation time $T_{c}$, etc. .

It was proven by Zaika (1973) that in stable age distribution populations, the P:B equals the birth rate $b$. Thus the overall population turnover rate for this population was calculated as $P: B=0.18$ day $^{-1}$, corresponding to 65 year $^{-1}$. This $P: B$ can be partitioned among the different life history stages as follows.

The juvenile body growth was studied at $17^{\circ} \mathrm{C}$ (Fig. 1). It can be described very well by the exponential function $\mathrm{W}_{t}=\mathrm{W}_{0} \mathrm{e}^{\mathrm{Gt}}$ where $\mathrm{W}_{\mathrm{t}}$ is the wet weight at time $t$, and $W_{0}$ and $G$ are constants. The parameters of this equation are $\mathrm{W}_{0}=0.014 \mu \mathrm{g} \mathrm{wwt}$, $\mathrm{G}=0.37 \mathrm{day}^{-1}\left(\mathrm{r}^{2}=0.995 ; \mathrm{F}=1135\right)$. Taking into account the development times at $12^{\circ} \mathrm{C}$ and $17^{\circ} \mathrm{C}$, the growth rate $\mathrm{G}$ at $12^{\circ} \mathrm{C}$ becomes $0.21 \mathrm{day}^{-1}$. Because of the exponential fit, this figure also equals the juvenile P:B.

Egg deposition occurs at a nearly constant rate of 5.1 eggs per female alive per day, until after about 40 days senescence starts rather abruptly, and almost no eggs are deposited any more.

Neglecting adult somatic growth, which is not important in stable age distributions as most adults

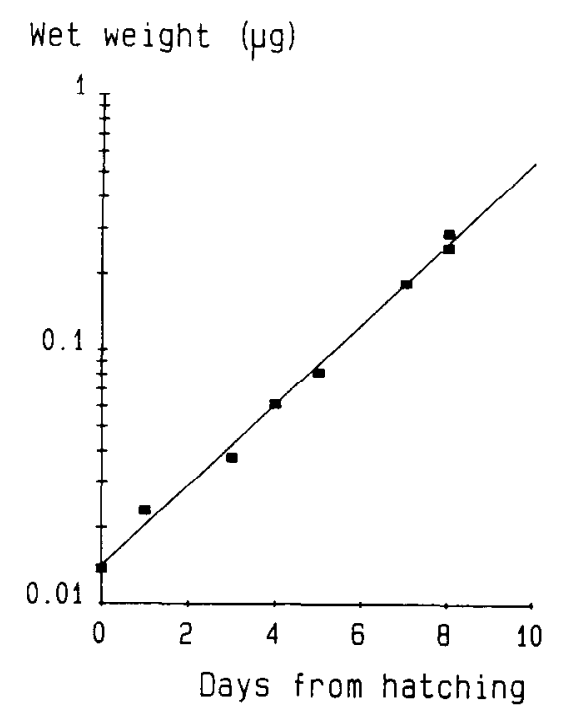

Fig. I. $M$. disjuncta: juvenile body growt hetween hatching and adulthood in agar cultures at $17^{\circ} \mathrm{C}$. 
are very young, the adults' $P: B$ is given by the formula:

$$
\begin{aligned}
\mathrm{P}: \mathrm{B}= & (1 / \text { adult weight }) \times \text { no. eggs produced } / \\
& \text { female day } \times \text { egg weight } \times \text { fraction } \\
& \text { females }
\end{aligned}
$$

The P: B equals $0.33 \mathrm{day}^{-1}$. As was mentioned before, if we calculate the adults' $P: B$ with the egg's weight, we must incorporate a negative production in the egg stage. In this case, this egg P:B amounts to -0.13 day $^{-1}$. Alternatively, we can calculate the adults' $P$ : B by taking into account only the weight of the neonates. The adult P:B then becomes 0.20 day $^{-1}$, almost exactly equal to the juvenile $P: B$.

Because of this equality, the population's age structure can only affect its P: B through adult body growth, which however we think is not very important in this case. Thus the population P:B equals the juvenile P:B which, due to the exponential growth is given by:

$$
\mathrm{P}: \mathbf{B}=\ln \left(\mathrm{W}_{\mathrm{T}} / \mathrm{W}_{0}\right)=\mathrm{G} \mathrm{T}
$$

per developmental period, where $\mathrm{W}_{\mathrm{T}}$ and $\mathrm{W}_{0}$ are the body weights at the end and the start of the juvenile period respectively, and $T$ is the developmental period.

This figure gives a reliable estimate of the population $P: B$ because the following conditions are met: 1. The neonates' weight is called 'production', or a term for 'negative production' in the egg stage is incorporated in the budget.

2. The juvenile body growth is exponential.

3. The adult body growth is not too important.

4. The productivity of the (young) adults is not much different from the juvenile productivity.
It is not clear whether the last three conditions can be generalized to nematodes as a group, and thereby provide a justification for the use of an overall figure for $\mathrm{P}: \mathrm{B}$ per developmental period. The available information suggests that juvenile growth in nematodes does not depart too widely from an exponential model. Table 3 gives some approximate values for $\ln \left(W_{T} / W_{0}\right)$, showing that this value does not vary too widely either.

The most important condition then becomes 4 . This condition is rather difficult to check in published studies. Intuitively one would expect that the weight-specific production of adults defined in terms of neonates' weight cannot be higher than the weight-specific production of the juveniles. In general, the intensity of metabolism decreases with age. Although the data on $M$. disjuncta suggest a fairly constant rate, it may in fact decrease after the first days of adulthood, if the adults have some somatic growth.

An unresolved problem in these data is the allocation of the adults' production between the sexes. As the weight-specific production of the adults, as a whole, is almost equal to the juveniles', females have a higher productivity than juveniles, and males a much lower one. Whatever the mechanism is that allows females to have a higher productivity than juveniles, it is difficult to understand why this has not evolved in the juvenile stage. Possibly the hypothesis that male sperm contributes to the energy stored in the eggs (Warwick, 1981 a; Jennings \& Deutsch, 1975) could explain these data. On the other hand, observations by Jensen (1982) have made this hypothesis less probable.

\begin{tabular}{|c|c|c|c|}
\hline \multirow{2}{*}{$\frac{\text { Species }}{\text { Monhystera disjuncta }}$} & \multicolumn{3}{|c|}{$\ln \left(W_{T} / W_{0}\right)$} \\
\hline & 2.9 & $\left(17^{\circ} \mathrm{C}\right)$ & This paper \\
\hline Chromadora nudicapitata & 2.8 & $\left(12^{\circ} \mathrm{C}\right)$ & Vranken, unpubl. \\
\hline Monhystrella parelegantula & 2.3 & $\left(25^{\circ} \mathrm{C}\right)$ & $i d$ \\
\hline \multirow[t]{3}{*}{ Caenorhabditis hriggsae } & 3.5 & $\left(5 \times 10^{8}\right)$ & Schiemer, 1982a \\
\hline & 3.7 & $\left(10^{9}\right)$ & \\
\hline & 4.0 & $\left(10^{10}\right)$ & \\
\hline \multirow{2}{*}{ Plectus palustris } & 3.4 & $(1 \mathrm{~K})$ & Schiemer et al, 1980 \\
\hline & 3.6 & $(10 \mathrm{~K})$ & \\
\hline \multirow[t]{2}{*}{ Eudiplogaster pararmatus } & 4.1 & $\left(12^{\circ} \mathrm{C}\right)$ & Romeyn et al., 1983 \\
\hline & 2.3 & $\left(21^{\circ} \mathrm{C}\right)$ & \\
\hline Diplolaimelloides bruciei & 3.6 & $\left(20^{\circ} \mathrm{C}\right)$ & Warwick, $1981 \mathrm{a}$ \\
\hline
\end{tabular}

The conditions (1-4) stated above clarify the as-

Table 3. Natural logarithms of the ratio of final $\left(\mathrm{W}_{\mathrm{T}}\right)$ to initial $\left(\mathrm{W}_{0}\right)$ weight of nematode juveniles. See text for details. Number in brackets for $C$. briggsae and $P$. palustris refer to bacterial densities. 
sumptions by which a $\mathbf{P}: \mathbf{B}=\mathbf{3}$ per 'generation time' may be expected in nematodes. At the same time, it is demonstrated that the juvenile developmental period should be used as the (previously ill-defined) 'generation time'.

\section{Conclusions}

From our discussions we can make a few generalizations about meiofaunal productivity. We have argued that there is no evidence for a difference in production efficiency between meiofauna and other ecological groups. The conditions for the use of a $\mathrm{P}: \mathrm{B}=3$ per juvenile development period have been stated. They seem to apply well to nematode populations. This adds confidence to the graph given by Heip et al. (1982), which shows that the P:B body weight line for meiobenthos in Banse \& Mosher (1980) fits the data rather well. Thus the statement of these authors that a relatively low productivity is a definition criterion for meiofauna, is corroborated, although not proven.

Apart from these general considerations, however, considerable problems remain if one wishes to estimate the production of a population for which only biomass estimates are available. In particular, the estimations based on a constant production efficiency, and those based on a P:B body weight relationship may be inconsistent. Warwick \& Price (1979) noted that, after correction for temperature, the community respiration of nematodes nearly equalled $6 \mathrm{llO}_{2} \mathrm{~g} \mathrm{wwt}^{-1} \mathrm{a}^{-1}$ in several different habitats: the Lynher mudflat (UK), two salt marshes in Massachusetts (USA) (Wieser \& Kanwisher, 1961), a salt marsh in Georgia(USA) (Teal \& Wieser, 1966). For the coastal area and a sand bank in the Southern North Sea (data in Heip et al., 1984) these values are 5.53 and $5.871 \mathrm{O}_{2} \mathrm{~g} \mathrm{wwt}^{-1} \mathrm{a}^{-1}$ respectively. This constantcy is remarkable (and problematic) as the mean individual weight of a nematode in these habitats differs by more than an order of magnitude (range 0.33-8.64 $\mu \mathrm{g} \mathrm{wwt}$ ind.$^{-1}$ ). Assuming a constant efficiency for all species would result in a constant $P: B$, whereas a weight dependence in P:B would give P:B-differences by about a factor 8. Presumably it is the constant efficiency assumption which is violated in this instance. The large predatory: omnivorous nematodes (mainly Oncholaimida) have a high respiratory intensity
(Warwick \& Price, 1979) while it is known at least for a few species that they have only one to two generations a year in the field (Smol et al., 1980; Wieser \& Kanwisher, 1961; Skoolmun \& Gerlach, 1971).

\section{Acknowledgements}

P. Herman and C. Heip acknowledge a grant of the Belgian National Foundation for Scientific Research (NFWO); G. Vranken acknowledges a grant of the Belgian Institute for the Encouragement of Scientific Research in Industry and Agriculture (IWONL). Part of this research was supported by the Environmental Program of the EEC (contract no. ENV $566 \mathrm{~B}$ ) and by the Belgian Ministry of Science Policy (Concerted Actions Oceanography).

\section{References}

Banse, K., 1979. On weight dependence of net growth efficiency and specific respiration rates among field populations of invertebrates. Oecologia (Berl.) 38: 111-126.

Banse, K. \& S. Mosher, 1980. Adult body mass and annual production/ biomass relationships of field populations. Ecol. Monogr. 50: 355-379.

De Cuyper, C.\& J. R. Vanfleteren, 1982. Oxygen consumption during development and aging of the nematode Caenorhabditis elegans. Comp. Biochem. Physiol. 73A: 283-289.

Feller, R. J., 1982. Empirical estimates of carbon production for a meiobenthic harpacticoid copepod. Can. J. Fish. aquat. Sci. 39: 1435-1443.

Fleeger, J. W. \& M. A. Palmer, 1982. Secondary production of the estuarine, meiobenthic copepod Microarthridion littorale. Mar. Ecol. Prog. Ser. 7: 157-162.

Gerlach, S. A., 1971. On the importance of marine meiofauna for benthos communities. Oecologia (Berl.) 6: 176-190.

Heip, C., 1977. On the evolution of reproductive potentials in a brackish water meiobenthic community. Mikrofauna Meeresboden 61: 105-112.

Heip, C., P. M. J. Herman \& A. Coomans, 1982. The productivity of marine meiobenthos. Acad. Annal. 44: 1-20.

Heip, C., R. Herman \& M. Vincx, 1984. Variability and productivity of meiobenthos in the Southern Bight of the North Sea. R. P.-v. Réun. Cons. int. Explor. Mer. 183:51-56.

Heip, C. \& N. Smol, 1976. Influence of temperature on the reproductive potential of two brackish-water Harpacticoids (Crustacea, Copepoda). Mar. Biol. 45: 255-260.

Herman, P. M. J. \& C. Heip, 1982. Growth and respiration of Cyprideis torosa .Jones 1850 (Crustacea, Ostracoda). Oecologia (Berl.) 54: 300-303.

Herman, P. M. J. \& C. Heip, 1983. The respiration of five brackish-water harpacticoid species. J. exp. mar. Biol. Ecol. 71: 249-256. 
Hermann, P. M. J., C. Heip \& B. Guillemijn, 1984. Production of Tachidius discipes Giesbrecht 1881 (Copepoda: Harpacticoida). Mar. Lcol. Prog. Ser. 17: 271-278.

Herman, P. M. J., C. Heip \& G. Vranken, 1983. The production of Cyprideis torosa Jones 1850 (Crustacea: Ostracoda). Oecologia (Berl.) 58: 326-331.

Hicks, G. R, F. \& B. C. Coull, 1983. The ecology of marine meiobenthic harpacticoid copepods. Oceanogr. mar. Biol. Ann. Rev. 21: 67-175.

Humphreys, W. F., 1979. Production and respiration in animal populations. J. anim. Ecol. 48: 427-453.

Jennings, J. B. \& A. Deutsch, 1975. Occurence and possible adaptive significance of $\beta$-glucoronidase and arylamidase ('leucine aminopeptidase') activity in two species of marine nematodes. Comp. Biochem. Physiol. 52A: 611-614.

Jensen, P., 1982. Reproductive behaviour of the free-living marine nematode Chromadorita tenuis. Mar. Ecol. Prog. Ser. 10: 89-95.

Marchant, R.\& W. L. Nicholas, 1974. An energy budget for the free-living nematode Pelodera (Rhabditidae). Oecologia (Berl.) 30: 111-127.

Romeyn, K., L. A. Bouwman \& W. Admiraal, 1983. Ecology and cultivation of the herbivorous brackish-water nematode Eudiplogaster pararmatus. Mar. Ecol. Prog. Ser. 12: 145-153.

Schiemer, F., 1982a. Food dependence and energetics of freeliving nematodes, 1 . Respiration, growth and reproduction of Caenorhabditis briggsae (Nematoda) at different levels of food supply. Oecologia (Berl.) 54: 108-121.

Schiemer, F., 1982b. Food dependence and energetics of freeliving nematodes, 2. Lifc history parameters of Cacnorhabditis briggsae (Nematoda) at different levels of food supply. Oecologia (Berl.) 54: 122-128.

Schiemer, F, A. Duncan \& R. Z. Klekowski, 1980. A bioenergetic study of a benthic nematode, Plectus palustris de Man
1880, throughout its life cycle. Oecologia (Berl.) 44: 205-212.

Skoolmun, P. \& S. A. Gerlach, 1971. Jahreszeitliche Fluktuationen der Nematodenfauna im Gezeitenbereich des WeserAstuars. Veröff. Inst. Meeresforsch. Bremerh. 13: 119-138.

Smol, N. \& C. Heip, 1974. The culturing of some harpacticoid copepods from brackish water. Biol. Jb. Dodonaea 42 : 159-169.

Smol, N., C. Heip \& M. Govaert, 1980. The life cycle of Oncholaimus oxyuris (Nematoda) in its habitat. Ann. Soc. r. zool. Belg. 110: 87-103.

Teal, J. M. \& W. Wieser, 1966. The distribution and ecology of nematodes in a Georgia salt marsh. Limnol. Oceanogr. 11: 217-222.

Tietjen, J. H., 1980. Microbial-meiofaunal interrelationships: a review. Microbiology 335-338.

Warwick, R. M., 1981a. The influence of temperature and salinity on energy partitioning in the marine nematode Diplolaimelloides bruciei. Oecologia (Berl.) 51: 318-325.

Warwick, R. M., 1981b. Survival strategies of meiofauna. In N. V. Jones \& W. J. Wolff (eds.), Feeding and Survival Strategies of Estuarine Organisms. Plenum Press, N.Y.: 39-52.

Warwick, R. M. \& R. Price, 1979. Ecological and metabolic studies on free-living nematodes from an estuarine mud-flat. Estuar. coast. mar. Sci. 9: 257-271.

Waters, T. F., 1969. The turnover ratio in production ecology of freshwater invertebrates. Am. Natur. 103: 173-185.

Waters, T. F., 1977. Secondary production in inland waters. Adv. ecol. Res. 10: 91-164.

Wieser, W. \& J. Kanwisher, 1961. Ecological and physiological studies on marine nematodes from a salt marsh near Woods Hole, Massachusetts. Limnol. Oceanogr. 6: 262-270.

Zaika, V. E., 1973. Specific Production of Aquatic Invertebrates. Halsted Press. John Wiley \& Sons, N.Y., Toronto, 154 pp. 